\title{
Conventional and Biotechnological Approaches for Enhancing the Shelf-life of Fruits and Vegetables: A Review
}

Navjeet Kaur ${ }^{1}$, Trina Adhikary ${ }^{2}$, Amardeep Singh ${ }^{1}$

10.18805/ag.R-2252

\begin{abstract}
Due to highly perishable nature and less shelf-life, post-harvest losses of fruit and vegetables results in high gap between production and availability. Various plants traits which need to be genetically modified for higher shelf-life includes lowered rate of respiration and ethylene production, less sensitivity to ethylene, lowering ripening rate, reduced browning, decreased chilling sensitivity and increased postharvest disease resistance. The importance of understanding the biochemical process of softening and the use of such information for retarding the ripening process has been demonstrated in this paper. After reviewing the development made in extending the shelflife of fruits, it becomes evident that although success in this field has been inadequate, there are possibilities that fruit breeders will succeed in near future in evolving superior cultivars with longer shelf-life.

Key words: Biotechnological, Conventional, Horticultural crops, Post-harvest, Shelf-life.
\end{abstract}

Twenty years ago, consumers only ate fruits and vegetables that was "in season". Because there were no proper technologies to store the fruits for longer period. It is estimated that around $35-40 \%$ of all fresh fruits and vegetables are lost due to excessive softening, but the exact figure is hard to determine (Meli et al. 2010). Fruits and vegetables need to be stored as they have short post-harvest shelf-life. Shelf-life of fruits and vegetables means how long they will last. Shelf-life of fruit is directly related to ripening process. Ripening is an irreversible process which makes the fruits edible and constitutes, physiologically and commercially, the most significant phase in their life. As ripen, fruits become very soft and more prone to injuries, which make them highly perishable. Physiologists and biochemists attempted to extend the shelf-life of fruits by different means though the results were not satisfying. Pre-harvest factors and post-harvest treatments both contribute to shelf-life of fruits and vegetables. Earlier various treatments were given to fruits and vegetables to enhance the shelf-life. Now a day, biotechnological techniques also used for enhancing the shelf-life of horticultural produce. As we know main hormone responsible for the ripening is ethylene. Methionine is precursor of ethylene responsible for ripening of the fruits. Methionine is converted into S-adenosyl methionine (SAM) by adometsynthetaseenzyme. SAM is further converted into 1-aminocyclopropane-1-carboxylic acid (ACC) by ACC synthase enzyme and into methylthioadenosine. Now methylthioadenosine is converted into methionine again which continue the synthesis of ethylene. ACC is converted into ethylene by ACC oxidase enzyme (Abano and Buah, 2014).

\section{Effect of ethylene on fruit}

Ethylene affects quality of fruit by different ways. Acids are neutralized by kinase enzymes. Starch is converted into sugar by amylase enzyme. Chlorophyll is degraded by
${ }^{1}$ Department of Agriculture, Khalsa College, Amritsar-143 002, Punjab, India.

${ }^{2}$ College of Horticulture and Forestry, Punjab Agricultural University, Ludhiana-141 004, Punjab, India.

Corresponding Author: Navjeet Kaur, Department of Agriculture, Khalsa College, Amritsar-143 002, Punjab, India.

Email: randhawanav2020@gmail.com

How to cite this article: Kaur, N., Adhikary, T. and Singh, A. (2022). Conventional and Biotechnological Approaches for Enhancing the Shelf-life of Fruits and Vegetables: A Review. Agricultural Reviews. DOI: 10.18805/ag.R-2252.

Submitted: 05-05-2021 Accepted: 02-12-2021 Online: 28-01-2022

hydrolase enzyme. Pectin which is present in hard form first is converted into softer pectin by pectinase enzyme. Large molecules lead to produce increased fragrance by hydrolase enzymes. Means ripening of fruits is coordinated by function of various enzymes. All these activities of ethylene in ripening process makes fruit edible and leads to perishability of the fruit (Shankar, 2016).

\section{Conventional approaches}

Breeding methods recommended for improving Shelflife of fruits and vegetables

\section{Domestication}

It involve bring out the wild plant species under human management. It is observe that domestication of fruits involves a combination of genetic events including an increase in storage andshelf-life as compared to their wild counterparts (Singh and Singh, 2011).

\section{Introduction}

Plant introduction consists of taking a genotype or a group of genotypes of plants into a new area or region where they were not being grown before. It is of two types: 
a) Primary introduction: When the introduced variety is well adapted to the new environment, it is released from commercial cultivation without any alternation in its genotype, it constitutes primary introduction.

b) Secondary introduction: The introduced variety may be subjected to selection or used in a hybridization programme to develop a superior variety, it constitutes secondary introduction.

Apple var. Jonathan, Early $\mathrm{Gr}$ ande Peach, Kinnow m andarin, Solo papaya etc are good examples as they all have better shelf-life.

\section{Chance seedlings}

A chance seedling is the name given to a fruit cultivation discovered by chance seedling without any sustained breeding efforts. In fact, chance seedlings are superior naturally occurring variety in a plant population. Mango var. Alphonso, Banganpalli, Dashehari, Ambri apple and Guava variety Apple colour and Harijha are originated as chance seedlings having higher shelf-life.

\section{Selection}

Selection is basic to plants for longer shelf-life. It is the oldest procedure in which the individual plant or group of plants are sorted out from mixed population, thus eliminating undesirable one's.

\section{Hybridization}

Mating or crossing of two plants or lines of dissimilar genotype is known as hybridization. The main objective of hybridization is to create genetic variations for better fruit quality and better shelf-life of fruits. In certain cases, hybrids show higher shelf-life and better fruit quality traits than parent.

\section{Polyploids}

It is an important approach to confer desirable characteristics in some fruits. Sunny Rouge, a new early ripening and tetraploid grape (Vitis labruscana $\times$ Vitis vinifera) was obtained by crossing Pione $\times$ Red Pearl. It has tolerance to major pre and post-harvest diseases and exhibits good shelflife. Dark Ridge, a new tetraploid grape obtained from cross between Kyoho and 301-1 (Kyoho × Niabell). Dark Ridge fruits rarely crack and have good keeping quality (Singh and Singh, 2011).

\section{Mutation breeding}

Spontaneous and induced mutations may results into potentially novel genotypes with considerably higher shelflife. Mutants with increased sugar content and extended shelf-life have been reported in pears.

Castel Gala is a low chilling apple mutant with very early fruit ripening. Although their fruits ripe much earlier than those of Gala, fruits of both cultivars have almost similar storage characteristics and shelf-life (Singh and Singh, 2011).

\section{TWO TYPES OF FACTORS INFLUENCE THE SHELF- LIFE OF FRUITS AND VEGETABLES}

\section{Pre-harvest factors}

Environmental factors

\section{Temperature}

During fruit development, high temperature can affect photosynthesis, respiration, aqueous relations, membrane stability as well as level of plant hormones, primary and secondary metabolites which affect the quality as well as post-harvest life of fruit. Warm days and cool nights during growth are necessary for the full development of color at the ripe stage (Asrey and Barman, 2011).

\section{Sunlight}

Fruits which are exposed to sun are having thinner peel, higher soluble solid content, lower in acidity than those fruits which are grown in shade inside the canopy. Further, the intensity and duration of light affect the quality of fruit after harvest.

Wind

It may cause damage to the fruits. Mild wind velocity causes wind scarring disorder when the fruits are rubbed against twigs. This leads to poor keeping quality of the fruits.

\section{Frost and hail damage}

Hail damage is sporadic but worldwide more extensive than it is generally thought and it directly affect physical quality of horticultural produce and also increases the incidence of diseases.

\section{Cultural factors}

\section{Mineral nutrition}

Excess or deficiency of certain elements can affect shelflife of fruits. High levels of nitrogen lead to poor keeping quality of fruit. Phosphorus level in soil and plant does not have much effect on internal fruit quality but it certainly affects the fruit appearance also. Calcium sprays have beneficial effects. Iron and zinc deficiency results into reduced fruit size and poor color development (Karemera et al. 2014).

\section{Organic production}

Market for organically produced food is increasing. Organic production excludes the use of synthetic pesticides and fertilizers and allows use of animal and green manure, compost and botanical insecticides etc. There is conflicting information on the effects of organic production of fruits on their post-harvest characteristics but mainly organically produced fruits have poor keeping quality.

\section{Irrigation}

Careful manipulation of water supply may well decrease water usage and improve fruit quality without compromising sustainable plant growth. 


\section{Pruning, thinning and girdling}

Pruning can improve the light penetration into the canopy of the fruit tree. Fruitlet thinning increases size of fruit but reduces the yield. So, a balance between fruit size and yield must be maintained. Girdling has been found beneficial in grape and jackfruit. Heavy pruning of Kinnow improved yield as well as quality (Ahmad et al. 2006).

\section{Rootstock}

Fruit trees grafted on to rootstocks for different reasons. 'Jonagold' apples grown on rootstock PB-4 and M-26 showed lower ethylene production and delayed ripening during storage (Tomala et al. 2010).

\section{Tree age}

'Aroma' apples produced on young trees was higher in acid/ SSC ratio, better coloration and flavor quality as compared to old trees. But, fruit produced in old trees were more firm, and better storage potential (Tahir et al. 2007).

\section{Canopy position}

It also affects the quality of the fruit. Fruits which grow inside canopy remain green whereas fruits outside canopy develop red color.

\section{Genotype and cultivar}

Genotype and cultivar selection are major factors involved in post-harvest quality and shelf-life outcomes of the fruits and vegetables.

\section{Growth regulators}

Pre-harvest spray of GA3 application extended storage life of persimmon fruit by delaying both black spot development and fruit softening when stored at $-10^{\circ} \mathrm{C}$. It also delayed ripening and climacteric rise of respiration (Eshel et al. 2000).

\section{Post-harvest treatments}

These are the treatments which are given to after harvesting which enhances their shelf-life. This includes following treatments:

\section{lonizing radiations}

Irradiation has been used for years in food preservation with different applications depending upon the applied dose. Low doses alter physiological processes such as sprouting or life cycle of insect pest and fruit ripening. The dose of ionizing radiation i.e. 1.0 to $3.0 \mathrm{kGy}$ extends shelf-life of fresh fish and seafood, fruits and vegetables and 0.5 to $1.0 \mathrm{kGy}$ delays ripening in fresh fruits (Loaharanu, 2007).

\section{Heat treatments}

Heat treatments are like hot water, hot air and vapour heat treatment. Hot water treatment is mainly used for fungal organisms, vapour heat treatment is used for insects and hot air can be used for both. 14 days of shelf-life was observed in strawberries at $00 \mathrm{C}$ with hot air treatment at $45^{\circ} \mathrm{C}$ for $3 \mathrm{hr}$ (Vicente et al. 2002).

\section{Edible coatings}

These are thin layer of material which can be consumed and provides barrier to moisture, oxygen and solute movement for the food. All these coatings have different advantages and disadvantages. These coatings can be adopted depending upon the need of the fruits eg. in strawberries, papayas, apples and pears. Mainly edible coatings are like cellulose derivatives, starch, lipid films, shellec resins, protein films, chitin and chitosan.

\section{Modified atmosphere packaging}

MAP was first recorded in 1927 as an extension of the shelflife of apples by storing them in atmospheres with reduced $\mathrm{O}_{2}$ and increased $\mathrm{CO}_{2}$ concentrations. MAP is a cheap and convenient packaging system that has the capacity to extend shelf-life of fruit if it is used properly (Sandhya, 2011).

Shrink wrapping of high value temperate fruits for enhancing shelf-life

\begin{tabular}{lcccc}
\hline \multirow{2}{*}{ Fruit } & \multicolumn{2}{c}{$\begin{array}{c}\text { Shelf-life at room } \\
\text { temperature (days) }\end{array}$} & $\begin{array}{r}\text { Shelf-life in zero energy } \\
\text { cool chamber (days) }\end{array}$ \\
\cline { 2 - 5 } & Unwrapped & Wrapped & Unwrapped & Wrapped \\
\hline Apple & 21 & 30 & 35 & 45 \\
Kiwifruit & 9 & 14 & 11 & 20 \\
\hline
\end{tabular}

(Sharma and Pal, 2009).

\section{Calcium treatments}

High calcium content in fruits has been related to longer post-harvest life as a result of reduced rates of respiration and ethylene production. This effect has been attributed to decrease in activity of 1-aminocyclopropane-1-carboxylic acid (ACC).

\section{Gibberellic acid}

The use of Gibberellic acid as anti senescent regulator has been found to enhance the shelf-life in many fruits by their antagonistic effect on ethylene biosynthesis. Gibberellic acid inhibits ripening in fruit by decreasing respiration, delaying anthocyanin synthesis, chlorophyll degradation (Martinez et al. 1994).

\section{Salicylic acid}

Application of salicylic acid has been determined to delay ripening in a number of fruits by reducing the activities of major cell wall degrading enzymes like cellulase, polygalacturonase and xylanase and by suppressing ACC synthase and ACC oxidase (Asghari and Aghdam, 2010).

\section{Polyamines}

Ethylene and polyamines exhibits an opposite effect on fruit ripening and senescence, since reduced levels of PAs have been correlated with increased ethylene production, fruit ripening and senescence while high endogenous concentration of PAs associated with delay in these processes. 


\section{1-methylcyclopropene}

The ethylene action inhibitor 1-MCP has become an important tool to maintain the quality of selected fruit in supply chain. Delayed softening and firmness retention are the most notable responses of climacteric fruit to 1-MCP. It was commercially approved on July 2002 in apples, apricots, avocados, kiwifruit, mangoes, nectarine, papayas, peaches, pears, persimmons, plums, and tomatoes (Almeida, 2011).

\section{Biotechnological}

\section{Need of biotechnology}

There was need of biotechnology because one of the most recent methods by which an effective shelf-life extension could be achieved by genetically modified plant whereby expression of gene responsible for ripening could be regulated. Ability to maintain shelf-life of fruits and vegetables during post-harvest storage is highly related to physiological, biochemical and molecular traits of the plants from which they derive. These traits are genetically determined and can be manipulated using genetic breeding and biotechnology. Genetic transformation provides the means for modifying single horticultural traits without altering the phenotype (Abano and Buah, 2014).

\section{History: Flavr Savr tomato}

The delayed ripening tomato fruit 'Flavr Savr' was first commercially grown genetically engineered food to be approved for human consumption. It was produced by Cal gene, USA in 1992 and was first sold in 1994 and was only available for a few years, there after production of this tomato was stopped because of its high cost and low yield. The Flavr Savr tomato was genetically altered to synthesize an antisense RNA of a ripening related gene polygalacturonase $(P G)$, which is involved in dissolving cell-wall pectins, leading to fruit softening therefore, the fruit stays firm for longer periods (Dias and Ortiz, 2012).

\section{Biotechnological techniques being used}

\section{Antisense RNAs}

It means to effectively turning off gene expression of a key enzyme of ripening process by means of its antisense RNA. Antisense RNAs are long stretch of sequences that are complimentary to the sense RNA. They are very specific to the target genes and cause reduction of sense RNA by interfering with transcription and translation process (Surendranathan, 2005). PG-ase is one of the key enzymes involved in ripening-associated softening of fruits. This known to have effect on PG activity which is involved in dissolving pectins and causing softening therefore fruit stay firm for longer period. The cDNA from ACC oxidase gene when expressed in an antisense orientation caused a decrease in ethylene biosynthesis and delayed post-harvest ripening of tomato fruit.

Modification of ethylene biosynthesis through genetic engineering: In this, two types of genes may be used.

\section{Over expression of $A C C$ deaminase gene}

ACC deaminase metabolizes ACC to $\alpha$-ketobutyrate. This gene has been isolated from Pseudomonas sp. and was expressed in transgenic tomato plants. This approach leads to $90-95 \%$ inhibition in ethylene production during ripening reduction in ethylene synthesis does not cause any vegetative phenotypic abnormalities, however fruits from these plants show delay in ripening and they remained firm for at least 6 weeks longer than the non-transgenic control fruits (Klee et al. 1991).

\section{Over expression of SAM hydrolase gene}

In this approach gene from bacteriophage T3 which encodes the enzyme s-adenosylmethionine hydrolase (SAMase) has been utilized to generate transgenic tomato plants that produced fruits with a reduced capacity to synthesize ethylene. SAM is the metabolic precursor of 1aminocyclopropane-1-carboxylic acid, proximal precursor to ethylene. SAMase catalyzes the conversion of SAM to methylthioadenosine and homoserine thereby reducing synthesis of ethylene (Good et al. 1994).

\section{Use of polyamine genes}

The common PAs are putrescine, spermidine and spermine. Two pathways of polyamines and ethylene biosynthesis are seen to regulate each other, which is a decisive factor in determining the predominance of either of two pathways. Over expression of yeast spermidine synthase has been found to increase shelf-life in tomato (Nambeesan et al. 2010).

\section{RNAi approach}

RNAi, being a novel approach has great potential to modify the gene expression in plants for better quality traits and nutritional improvement in different crops. The post-harvest life can enhance by knocking-out genes responsible for ethylene production in tomato. This was achieved through introducing dsRNA and blocking the gene expression of ACC-oxidase which significantly reduced the ethylene formation and enhanced shelf-life in tomato. Use of n-glycan processing enzymes and cell wall modifying enzymes. Suppression of two ripening specific $\mathrm{N}$-glycoprotein modifying enzymes Alpha-mannosidase and Beta-D-Nacetyl hexosaminidase resulted in down regulation of cell wall degradation and ripening related genes in transgenic fruits. In tomato down regulation of these enzymes resulted in extended shelf-life of fruits (Meli et al. 2010).

\section{VIGS approach}

VIGS is a type of gene silencing approach. It has become an important tool in rapid and efficient functional analysis of genes by silencing action brought about by interfering RNA molecules delivered through modified viral infection of plant. In this when virus infect the plant there is dsRNA in virus which is broken into small nucleotides (23 nucleotides) called as siRNA (small interfering RNA) by a dicer present in the 
Conventional and Biotechnological Approaches for Enhancing the Shelf-life of Fruits and Vegetables: A Review

Engineering quality and delayed ripening of fruits

\begin{tabular}{llll}
\hline Crop & Gene & Function & References \\
\hline Tomato & ACC deaminase & Ethylene suppression & Chadha et al. 2000 \\
Papaya & Polygalacturonase & Suppressing synthesis and activity of PG & Laurena et al. 2002 \\
& Pectin methyl esterase & Delay in softening of fruit & Chadha et al. 2000 \\
Mango & Endoglucanase & Suppress mango softening & Chourasia et al. 2008 \\
& Alcohol dehydrogenase & Delay in ripening and aroma production & Vasanthaiah et al. 2006 \\
Apple & Polygalacturonase & Suppressing degradation of cell wall & Gao et al. 2007 \\
Pear & ACC oxidase & Ethylene suppression & Chadha et al. 2000 \\
Strawberry & SAM transferase & Ethylene suppression &
\end{tabular}

RISC (RNA induced gene silencing complex) mechanism of host plant. Now the antisense str and of dsRNA is identified by RISC and antisense RNA combines with argonaute protein of RISC and forms a complex. This complex binds with complimentary genome in the host cell and silences the gene. VIGS has been used as an alternative approach to transgenic development and it was incorporated to delay ripening in tomato by suppressing the LeACS2, a member of ACC synthase gene by using tobacco rattle virus (TRV)-based VIGS method to knock down LeACS2 in tomato fruit after harvest, at mature green fruit stage (Xie et al. 2006).

\section{TILLING approach}

It is a technique that can identify polymorphisms (more specifically point mutations) resulting from induced mutations in a target gene by heteroduplex analysis. A variation of this technique, EcoTILLING represents a means to determine the extent of natural variation in selected genes in crops. This approach was used in melon plants for improving shelf-life by using gene ACC oxidase 1 (DahmaniMardas et al. 2010). It allocates the rapid and cost-effective detection of induced point mutations in populations of physical/chemically mutagenized individuals. Ethyl methane sulfonate (EMS) is mostly used and produce $G / C$ to $A / T$ transition by alkylating the $G$ residues and the alkylated $G$ resides to base pair with $T$ instead of pairing with $C$. The crop species whose genome sequence has been finished; TILLING can be used to find the alleles in gene of interest for biotic and abiotic stresses.

EcoTILLING, an extension of TILLING, is an inexpensive and rapid method of discovery and analysis of single-nucleotide polymorphism (SNP) in natural populations. In TILLING parental DNA sequence whereas in EcoTILLING genomic DNA sequences used to identify the mutations created using endonuclease (CEL I). These techniques are independent of genome size; ploidy level and reproductive system of plants. They can be applied not only to model organisms but also to economically important crops. These provide a powerful approach for gene discovery, DNA polymorphism assessment and linkage disequilibrium. It is concluded that the induced mutations and natural polymorphism can be identified by TILLING and EcoTILLING approaches and the next task is their implementations in crop breeding.

\section{Case studies}

Elitzur et al. (2016) conducted a research study on the influence of transcriptional factors to promote shelf-life in banana (Musa acuminate, AAA Cavendish subgroup, $\mathrm{Gr}$ and Nain are used for transformation by three trangenic genes such as RNAi MaMADS1, RNAi MaMADS2 and AS MaMADS2). They found that reducing the transcript levels of either MaMADS1 or S2 by RNAi approach which leads to decrease in ripening progression and delay shelf life of fruits.

Das et al. (2016) evaluated the expression of SAMDC gene for enhancing the shelf-life for improving the fruit quality using biotechnological approaches into litchi chinensis cultivars. They observed that S-adenosylmethionine decarboxylase acts on SAM and convert into polyamines so that very small amount of SAM is available to produce ethylene and consequently ripening process can be delayed and fruits shelf life can be enhanced.

Tanase et al. (2016) stated that berries are characterized by a shorter shelf-life than other fruits because of higher susceptibility to microbial spoilage, increased respiration rate and ethylene production which stimulate wounding of tissue. Simple and best method to keep them in refrigerated state at $10^{\circ} \mathrm{C}$ but this method is not always optimal i.e modified atmosphere packaging, edible coatings and films, UV light, ozone, dipping berries in different solutions.

Krishna et al. (2012) conducted an experiment for extension of shelf-life of apple cv. Oregon Spur by applying combination of mineral nutrition ( $\mathrm{Ca}$ and $\mathrm{B}$ ) and bioregulator (salicylic acid and GA3) during 60 days of storage under ambient conditions. They concluded that shelf-life and quality of apple was improved significantly by treating apple with combinations of nutrients and bioregulators rather than treating with single nutrient or bioregulator.

\section{CONCLUSION}

Both conventional and biotechnological approaches are used for enhancing shelf-life of fruits. It is evident that developed biotechnological approaches have the potential to enhance shelf-life of fruits and to meet dem and of $21^{\text {st }}$ century. Post-harvest treatments are mainly used in case of conventional approaches. In biotechnological approaches genetic engineering is the main technique. Both these approaches are known to have beneficial effects in enhancing shelf-life of horticultural crops in future. 


\section{REFERENCES}

Abano, E.E. and Buah, J.N. (2014). Biotechnological approaches to improve nutritional quality and shelf-life of fruits and vegetables. International Journal of Engineering and Technology. 4: 660-672.

Ahmad, S., Chatha, Z.A., Nasir, M.A., Aziz, A., Virk, N.A., Khan, A.R. (2006). Effect of pruning on yield and quality of Kinnow fruit. Journal of Agriculture and Social Research. 2: 51-53.

Almeida, D.P.F. (2011). Post-harvest application of 1-methylcyclopropene in fruit in post-harvest treatments and fruit quality and safety. 85-100.

Asghari, M. and Aghdam, M.S. (2010). Impact of salicylic acid on postharvest technology physiology of horticultural crops. Trends Food Science and Technology. 21: 502-509.

Asrey, R. and Barman, K. (2011). Effect of pre-harvest factors on post-harvest quality of fruits. Advances in Post-Harvest Treatments and Fruit Quality and Safety.193-208.

Atkinson, R.G., Schroeder, R., Hallet, I.C., Cohen, D., Mac Rea, E.A. (2002). Over expression of polygalacturonase in transgenic apple trees leads to a range of novel phenotypes involving changes in cell adhesion. Plant Physilogym. 129: 122-133.

Chadha, K.L., Ravindran, P.N., Shahjiram, L. (2000). Biotechnology in Horticulture and Plantation Crops, Malhotra Publishing House, New Delhi India. 1-25.

Chourasia, A., Sane, V.A., Singh, R.K., Nath, P., (2008). Isolation and characterization of the MiCel 1 gene from mango: Ripening related expression and enhanced endoglucanase activity during softening. Plant Growth Regulator. 56: 117-127.

Dahmani-Mardas, F., Troadec, C., Boualem, A., Le've^que, S., Alsadon, A.A., Aldoss, A.A., Dogimont, C., Bendahmane, A. (2010). Engineering melon plants with improved fruit shelf-lifeusing the TILLING approach. PLoS ONE. 5: e15776. doi:10.1371/journal.pone.0015776.

Das, D., Prabhakar, M., Kumari, D., Kumari, N., (2016). Expression of SAMDC gene for enhancing the shelf-life for improvement of fruit quality using biotechnological approaches into litchi (Litchi chinensis Sonn.) cultivars. Advances in Bioscience and Biotechnology. 7: 300-310.

Dias, J.S. and Ortiz, R. (2012). Transgenic vegetable crops: Progress, potentials and prospects. Plant Breeding Reviews. 35: 85-180.

Elitzur, T., Yakir, E., Quansah, L., Zhangjun, F., Vrebalow, J., Khyat, E., Giovannoni, J., Friedman, H., (2016). Banana MaMADS transcription factors are necessary for fruit ripening and molecular tools to promote shelf life and food security. Plant Physiology 171: 380-391.

Eshel, D., Ben-Arie, R., Dinoor, A., Prusky, D., (2000). Resistance of gibberellins-treated persimmon fruit to Alternaria alternata arises from the reduced ability of the fungus to produce endo-1,4- $\beta$-glucanase. Phytopathology. 90: 1256-1262.

Gao, M., Matsuta, N., Murayama, H., Toyomasu, T., Mitsushaahi, W., Abhya, D., Andekar, M., Tao, R., Nishimura, K., (2007). Gene expression and ethylene production inn transgenic pear (Pyrus communis cv. La France) with sense or antisense cDNA encoding ACC oxidase. Plant Science. 173: 32-42.
Good, X., Kellogg, J.A., Wagoner, W., Langhoff, D., Matsumura, W., Bestwick, R.K. (1994). Reduced ethylene synthesis by transgenic tomatoes expressing S-adenosylmethionine hydrolase. Plant Molecular Biology. 26: 781-790.

Karemera, N.J.U., Mukunda, G.K., Ansar, H., Taj, A. (2014). Effect of calcium chloride sprays on ripening, shelf-life and physico-chemical parameters and organoleptic evaluation of mango fruits (Mangifera indica L.) cv. Totapuri. Plant Archives. 14: 121-124.

Klee, H.J., Hayford, M.B., Kretzmer, K.A., Barry, G.F., Kishore, G.M. (1991). Control of ethylene synthesis by expression of bacterial enzyme in transgenic tomato plants. The Plant Cell. 3: 1187-1193.

Krishna, H., Das, B., Attri, B.L., Kumar, A., Ahmed, N. (2012). Interraction between different pre- and post-harvest treatments on shelf-life extension of 'Oregon Spur' apple. Fruits 67: 31-40.

Laurena, A.C., Magdalita, P.M., Hidalgo, M.S.P., Villegas, V.N., Mendoza, E.M.T., Botella, J.R. (2002). Cloning and molecular characterization of ripening-related ACC synthase from papaya fruit (Carica papaya L.). Proceeding of International Symposium on Tropical and Subtropical fruits. Acta Horticulture. 575: 163-169.

Loaharanu, P.M.S. (2007). Irradiated Foods. Sixth Edition. Edited R Kava. American Council on Science and Health. New York USA. P 1-47 URLs: https://www.acsh.org.

Martinez, G.A., Chaves, A.R., Anon, M.C. (1994). Effect of gibberellic acid on ripening of strawberry fruits (Fragaria annanassa Duch.). Journal of Plant Growth Regulators. 13: 87.

Meli, S.V., Ghosh, S., Prabha, T.N., Chakroborty, N., Chakroborty, S., Datta, A., (2010). Enhancement of fruit shelf-life by suppressing $\mathrm{N}$-glycan processing enzymes. Proceedings of the National Academy of Sciences of the United States of America. 107: 2413-2418.

Nambeesan, S., Datsenka, T., Ferruzzi, M.G., Malladi, A., Mattoo, A.K., Handa, A.K. (2010). Overexpression of yeast spermidine synthase impacts ripening, senescence and decay symptoms in tomato. The Plant Journal. 63: 836-847.

Sandhya (2011). Modified atmosphere packaging of fresh fruit. Advances in post-harvest treatments and fruit quality and safety. 209-222.

Shankar, S. (2016). Fruit Ripening Presentation.TamilNaduAgricultural University.

Sharma, R.R. and Pal, R.K.(2009). Shrink-wrapping high-value temperate fruits for enhancing shelf-life. ICAR News JulSept 1-2.

Singh, A. and Singh, A.K. (2011). Fruits and Vegetables with Longer Shelf-Life for Extended Availability in the Markets. In: Horti-business Delhi Agri-Horticultural Society. 131-135.

Surendranathan, K.K. (2005). Post-harvvest biotechnology of fruits with special reference to banana-prespective and scope. Indian Journal of Biotechnology. 4: 39-46.

Tahir, I.I., Johansson, E., Olsson, M.E., (2007). Improvement of quality and storability of apple cV Aroma by adjustment of some pre-harvest conditions. Scientia Horticulture. 112: 164-171. 
Tanase, E.E., Popescu, P.A., Popa, V.I., Popa, M.E. (2016). New techniques used to improve berries shelf life. Food and Veg. Processing. 4-6.

Tomala, G., Bocanegra, J.A., Martinez, G., Rpmeo, R., DuranZuazo, V.H., Muriel-Fernandez, J.L. (2010). Positive impact of regulated deficit irrigation on yield and fruit quality in a commercial citrus orchard [(Citrus sinensis L.) cv. salustiano]. Agricultural Water Management. 97: 614-622.

Vasanthaiah, H.K., Ravishankar, K.V., Shivashankara, K.S., Anand, L., Narayanaswamy, P., Mukunda, G., Prasad, T.G. (2006). Cloning and characterization of differently ezpressed gene off internal breakdown in mango fruit (Mangifera indica.). Journal of Plant Physiology. 163: 671-679.

Vicente, A.R.R., Martinez, G.A., Chaves, A.R., Civello, P.M. (2002). Quality of heat-treated strawberry fruit during refrigerated storage. Postharvest Biology and Technology. 25: 59-71.

Xie, Y.H., Zhu, B.Z., Yang, X.L., Zhang, H.X., Fu, D.Q., Zhu, H.L., Shao, Y., Li, Y.C., Gao, H.Y., Lyo, Y.B., (2006). Delay of postharvest ripening and senescence of tomato fruit through virusinduced LeACS2 gene silencing. Postharvest Biology and Technology. 42: 8-15. 